\title{
A Hybrid Technique for Upward Stabilization and Control of Two Wheeled Self-Balancing Segway
}

\author{
Sajid Iran khan ${ }^{1 a}$, Muhammad Ahmad Choudhry ${ }^{1 b}$, Ahsan Ali ${ }^{1 c}$, Inam Ul Hasan Shaikh ${ }^{1 d}$, \\ Faisal Saleem $^{1 \mathrm{e}}$
}

RECEIVED ON 08.04.2019, ACCEPTED ON 15.09.2020

\begin{abstract}
Two wheeled Self-Balancing Segway, which works on the principle of inverted pendulum, is naturally unstable, nonlinear, and under actuated system. Self-Balancing means the capability of the Segway to balance itself on two wheels without falling. Therefore, the system has to be controlled to reach stability in this unstable state. The two wheeled Segway is considered important due to its applications in daily life. In this paper, a hybrid control system is proposed for upward stabilization and control of two wheeled Segway. The control design approaches proposed in the literature for Segway result in a large control effort which requires high torque causing the saturation of actuator field and ultimately failure of the controller. Controller designed using the proposed approach is able to reduce the control effort by $64 \%$ compared to the ones available in literature. Moreover, controller designed through the proposed approach is able to improve disturbance rejection for both pitch and yaw angles of the Segway. Simulation results illustrate the effectiveness of the proposed approach over the ones available in the literature.
\end{abstract}

Keywords: Segway, Hybrid Control Design, Control Effort, Saturation, Disturbance Rejection

\section{INTRODUCTION}

$\mathrm{S}$ egway is a self-balancing vehicle and it balances the person riding on it [1]. Nowadays, Segway is commonly used as a mean of transport for law enforcement, city sightseeing tours and professionals working in factories [2].

Fig. 1 shows a schematic diagram of a Two wheeled Segway with the major components and directions labeled [3].

Mathematical model of a two wheeled Segway is based on that of inverted pendulum [4-6]. Two wheeled Segway is a nonlinear, unstable system having uncertain parameters and thus poses a great deal of challenges while designing the control system. A comprehensive design of Two Wheeled Mobile Robot

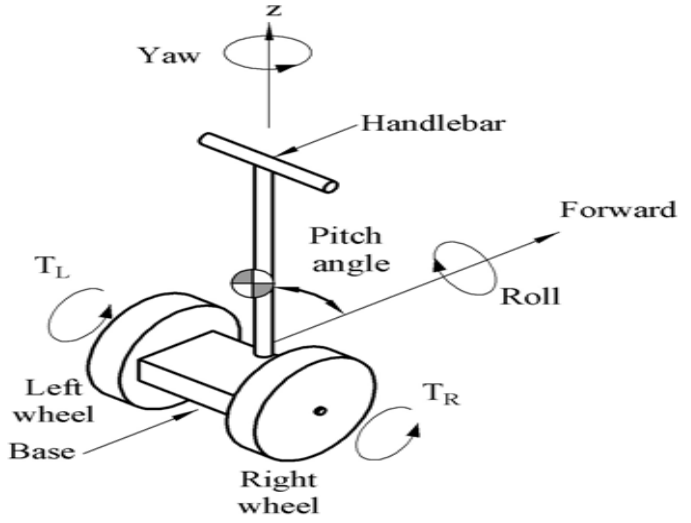

Fig. 1: Schematic Diagram of Two Wheeled Segway

(TWMR) are addressed in [7-8]. Issues related to selection of sensors and actuators, control scheme, signal processing units and modelling are addressed in the afore-mentioned work. A simple control scheme for

${ }^{1}$ Department of Electrical Engineering, University of Engineering and Technology Taxila, Pakistan.

Email: engrsikhanniazi@gmail.com (Corresponding Author), ${ }^{b}$ Dr.ahmad@ uettaxila.edu.pk, ahsan.ali@uettaxila.edu.pk, dInam.hassan@uettaxila.edu.pk, ${ }^{\mathrm{d}}$ faisal.slaeem14@outlook.com

This is an open access article published by Mehran University of Engineering and Technology, Jamshoro under CC BY 4.0 International License. 
the Segway, based on pole placement method, has also been proposed there. Lin et al. [9] applied a simple PID control and state-feedback control using pole placement method for the Segway human transporter. Takei and Imamura [10] presented Linear Quadratic Regulator (LQR) approach for pitch angle control of self-balancing Segway. The approaches discussed above are based on nominal model and can only ensure the desired performance when the parameters of Segway remain constant.

Aside from the Linear Time Invariant (LTI), nonlinear methods are also proposed for the Segway in the literature. Yau et al. [11] and Wu et al. [12] proposed model for the two wheeled self-balancing robot and designed a sliding mode controller. The sliding mode combined with robust control is proposed for stabilization and disturbance rejection of two wheeled self-balancing robot. However, this also resulted in chattering in control effort due to the switching between sliding surfaces. Kokotovic [13] and Dumitrascu et al. [14] proposed the back stepping technique for the stabilization of two wheeled, they combined back stepping with sliding mode control to suppress the chattering in control effort.

Kausar et al. [15] studied the movement of two wheeled mobile Segway on inclined terrain to avoid the tip-over issue. The research work explained the adjustment for center of mass of the body to deal with the problem in balancing of Segway on an inclined surface. The LQR method was applied to design the controller. The controller was then tested for inclined and flat surfaces. The results revealed that for varying equilibrium point and stability region, the stability region of Segway motion on inclined terrain was reduced.

Park et al. [16] proposed a technique based upon adaptive neural sliding mode control for handling uncertainties in non-holonomic model of two wheeled self-balancing Segway robot. Uncertainties in model and external disturbances were approximated by using Self-Recurrent Wavelet Neural Networks (SRWNNs). The simulation results revealed the robustness and better performance of the proposed designed control system.

Tsai et al. [17] presented an adaptive control technique based on Radial Basis Function Neural Networks (RBDNNs) for two wheeled Segway. The pitch angle and yaw controls were achieved by adaptive controllers using RBFNNs. However, the NNs require a lot of time for training and in turn a large memory bank is required and also they may stuck up in local minima.

In the work of Pham and Lee [18] and Shilpa et al. [19], sliding mode control was applied for stability of two wheeled Segway. The advantage of sliding mode control technique was its insensitivity to the parameter uncertainties and modeling errors of the system.

Rashdi et al. [20] proposed a nonlinear control technique based on SMC for pitch, yaw, and altitude control of a quad copter. The robustness of the SMC design provided a better control design having good tracking performance as well as accuracy [20]. Similar approaches are also applied to the Segway, as mentioned above.

Son and Anh [21] proposed the technique of back stepping to control the tilt angle of the Segway. The main drawback of this technique was its complexity and results revealed that the control input effort given to the plant by the controller was very high. This problem is serious as the input depends upon the specifications of motors. The torques of the motors are limited and may cause saturation resulting in failure of the designed controller.

It is clear from the above discussion that the LTI control design approaches render quite large control effort while the nonlinear approaches result in chattering in the control effort. The chattering can be removed by combing the conventional nonlinear control design approaches, i.e. System Management Controller (SMS) or Backstepping, with the neural network but the resulting algorithm becomes computationally expensive. To avoid all these issues, a hybrid control approach using conventional LTI approaches has been proposed in this work. The major contributions of this work include:

- Application and validation of the proposed hybrid approach on Segway for stability and disturbance rejection

- Stabilization and disturbance rejection at a 
reduced control effort with no chattering

- Uncertainties due to the rider's mass have been compensated

Rest of the article is arranged as: Section 2 described the detailed mathematical modeling of the Segway. Section 3 discusses the proposed hybrid control design approach for the Segway. A detailed discussion about the simulation results have been provided in Section 4 and finally conclusions are drawn in Section 5.

\section{MATHEMATICAL MODELING OF THE SEGWAY}

This section describes the mathematical model of the two wheeled Segway. Basic laws of physics and Newton's method are applied to determine the mathematical equations of the Two-wheeled Segway. Coordinate system of the Segway is shown in Fig. 2. Segway model is derived by applying Newton's second law of motion on the system. Subscripts L stands for left and $\mathrm{R}$ for right sides of the Segway.

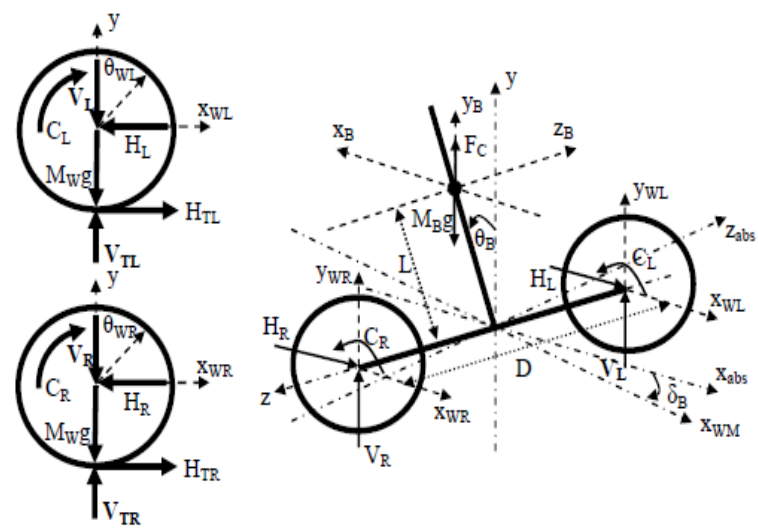

Fig. 2: Two Wheeled Segway Coordinate System

Equations (1-6) are for left wheel of the Segway (same for the right wheel).

$\mathrm{M}_{\mathrm{W}} \ddot{\mathrm{x}}_{\mathrm{wL}}=\mathrm{H}_{\mathrm{TL}}-\mathrm{H}_{\mathrm{L}}$

$\mathrm{M}_{\mathrm{w}} \ddot{\mathrm{y}}_{\mathrm{wL}}=\mathrm{H}_{\mathrm{TL}}-\mathrm{H}_{\mathrm{L}}$

$\mathrm{J}_{\mathrm{WL}} \ddot{\theta}_{\mathrm{wL}}=\mathrm{C}_{\mathrm{L}}-\mathrm{H}_{\mathrm{TL}} \mathrm{R}$

$\mathrm{x}_{\mathrm{WL}}=\theta_{\mathrm{wL}} \mathrm{R}$

$\mathrm{J}_{\mathrm{WL}}=\frac{1}{2} \mathrm{~m}_{\mathrm{WL}} \mathrm{R}^{2}$

$\delta=\frac{\mathrm{x}_{\mathrm{WL}}-\mathrm{x}_{\mathrm{WR}}}{\mathrm{D}}$
Equations (7-17) provide mathematical representation of the Segway body.

$\mathrm{M}_{\mathrm{B}} \mathrm{x}_{\mathrm{wB}}^{\ddot{*}}=\mathrm{H}_{\mathrm{L}}+\mathrm{H}_{\mathrm{R}}$

$M_{B} \ddot{y}=V_{L}+V_{R}-M_{B} g+\frac{C_{L}+C_{R}}{L} \sin \theta_{B}$

$\mathrm{J}_{\mathrm{B}} \ddot{\theta}_{\mathrm{B}}=\left(\mathrm{V}_{\mathrm{L}}+\mathrm{V}_{\mathrm{R}}\right) \mathrm{L} \sin \theta_{\mathrm{B}}-\left(\mathrm{H}_{\mathrm{L}+} \mathrm{H}_{\mathrm{R}}\right) \mathrm{L} \cos \theta_{\mathrm{B}}-$

$\left(\mathrm{C}_{\mathrm{L}}+\mathrm{C}_{\mathrm{R}}\right)$

$\mathrm{x}_{\mathrm{B}}=\mathrm{L} \sin \theta_{\mathrm{B}}+\frac{\mathrm{x}_{\mathrm{WL}}+\mathrm{x}_{\mathrm{WR}}}{2}$

$\mathrm{y}_{\mathrm{B}}=-\mathrm{L}\left(1-\cos \theta_{\mathrm{B}}\right)$

Where distance between the center of the gravity of Segway and body pitch inertia can be calculated as given in [22].

$\mathrm{L}=\left(\mathrm{M}_{\mathrm{S}}\left(\frac{\mathrm{H}_{\mathrm{B}}}{2}\right)+\mathrm{L}_{\text {rider }} \times 0.55 \times \mathrm{M}_{\text {rider }}\right) / \mathrm{M}_{\mathrm{B}}$

$\mathrm{J}_{\text {rider }}=\frac{1}{3} \mathrm{M}_{\text {rider }}$ Lrider $^{2}$

$\mathrm{J}_{\mathrm{B}}=\mathrm{J}_{\text {rider }}+1.49$

$\theta=\theta_{\mathrm{B}}=\theta_{\mathrm{w}}=\theta_{\mathrm{wL}}=\theta_{\mathrm{wR}}$

$\mathrm{X}_{\mathrm{WM}}=\frac{\mathrm{x}_{\mathrm{WL}}+\mathrm{x}_{\mathrm{WR}}}{2}$

$\mathrm{J}_{\delta} \ddot{\delta}=\frac{\mathrm{D}}{2}\left(\mathrm{H}_{\mathrm{L}}+\mathrm{H}_{\mathrm{R}}\right)$

where HTR, HTL, HR, HL, VTR, VTL, VR, and VL denote the reaction forces on the different free bodies.

Substituting equations $(7,8,15)$ into equation $(9)$ gives equation (18)

$\mathrm{J}_{\mathrm{B}} \ddot{\theta}=\mathrm{M}_{\mathrm{B}}\left(\ddot{\mathrm{y}} \sin \theta-\ddot{\mathrm{x}}_{\mathrm{B}} \cos \theta\right)+\mathrm{M}_{\mathrm{B}} \mathrm{gL \operatorname {sin } \theta}-\left(\mathrm{C}_{\mathrm{L}}+\right.$ $\left.\mathrm{C}_{\mathrm{R}}\right)\left(1+\sin ^{2} \theta\right)$

Equation (19) is derived from equations $(10-11,16)$,

$\ddot{y}_{\mathrm{B}} \sin \theta-\mathrm{x}_{\mathrm{B}}{ }_{\mathrm{B}} \cos \theta=-\mathrm{L} \theta \cdot \mathrm{x}^{*}{ }_{\mathrm{WM}} \cos \theta$

Equation (20) is derived from substitution of equations $(14,17)$ into equation $(18)$.

$\frac{4}{3} \mathrm{M}_{\mathrm{B}} \mathrm{L}^{2} \ddot{\theta}+\mathrm{M}_{\mathrm{B}} \mathrm{L} \cos \theta \mathrm{x}_{\mathrm{wM}}^{\ddot{*}}=\mathrm{M}_{\mathrm{B}} \mathrm{gL} \sin \theta-(\mathrm{a}+$ $\left.\sin ^{2} \theta\right) C_{\theta}$

Manipulating equation (1) gives equation (21)

$\mathrm{M}_{\mathrm{W}}\left(\mathrm{x}_{\mathrm{wL}}^{\ddot{*}}+\ddot{\mathrm{x}_{\mathrm{wR}}}\right)=-\left(\mathrm{H}_{\mathrm{L}}+\mathrm{H}_{\mathrm{R}}\right)+\left(\mathrm{H}_{\mathrm{TL}}+\mathrm{H}_{\mathrm{TR}}\right)(21)$ Substituting equations $(3,7)$ into equation $(21)$ and simplifying. 
$\mathrm{M}_{\mathrm{W}}\left(\mathrm{x}_{\mathrm{wL}}^{\ddot{*}}+\mathrm{x}_{\mathrm{wR}}^{\ddot{*}}\right)=-\mathrm{M}_{\mathrm{B}} \ddot{\mathrm{x}}+$

$\frac{\mathrm{C}_{\mathrm{L}}+\mathrm{C}_{\mathrm{R}}-\left(\mathrm{JWL}_{\mathrm{WL}} \ddot{\theta}_{\mathrm{WL}}+\mathrm{J}_{\mathrm{WR}} \ddot{\theta}_{\mathrm{WR}}\right)}{\mathrm{R}}$

Equation (23) is derived from Equations $(10,14)$

$\mathrm{x}_{\mathrm{B}}=\ddot{\theta} \mathrm{L} \cos \theta+\dot{\theta} \mathrm{L} \cos \theta+\mathrm{x}_{\mathrm{w} \mathrm{L}}^{\ddot{*}}$

Substituting equations $(23,5)$ into equation $(22)$

$\left(M_{B} L \cos \theta+M_{W} R\right) \ddot{\theta}+\left(2 M_{W}+M_{B}\right) x_{w M}=$

$\dot{\theta}^{2} \mathrm{M}_{\mathrm{B}} \mathrm{L} \sin \theta+\frac{\mathrm{C}_{\theta}}{\mathrm{R}}$

From Equations (20,24), we have equations (25-26)

$\mathrm{A} \ddot{\theta}=\mathrm{B}_{1} \dot{\theta}^{2}+\mathrm{C}_{1} \mathrm{C}_{\theta}$

$\mathrm{Ax}_{\mathrm{wM}} \ddot{\mathrm{B}_{2}} \dot{\theta}^{2}-\mathrm{C}_{2} \mathrm{C}_{\theta}$

Equation (27) is derived from equations (1,3-4)

$\mathrm{H}_{\mathrm{L}}=\frac{\mathrm{C}_{\mathrm{L}}}{\mathrm{R}}-\ddot{\mathrm{x}_{\mathrm{WL}}}\left[\mathrm{M}_{\mathrm{W}}+\frac{\mathrm{JWL}_{\mathrm{WL}}}{\mathrm{R}^{2}}\right]$

From equation (6), we get:

$\ddot{\delta}=\frac{x_{\ddot{w} L}-x_{\ddot{w} R}}{D}$

From equations (27-28), we obtain:

$H_{L}-H_{R}=\frac{C_{L}-C_{R}}{R}-D \ddot{\delta}\left[M_{W}+\frac{J_{W}}{R^{2}}\right]$

Substituting equation (29) into equation (17), we have

$\left[\mathrm{J}_{\delta}+\frac{1}{2} \mathrm{D}^{2}\left[\mathrm{M}_{\mathrm{W}}+\frac{\mathrm{JW}}{\mathrm{R}^{2}}\right]\right] \ddot{\delta}=\frac{1}{2} \mathrm{D} \frac{\mathrm{C}_{\mathrm{L}}-\mathrm{C}_{\mathrm{R}}}{2}$

$\mathrm{J}_{\mathrm{W}}=\frac{1}{2} \mathrm{M}_{\mathrm{W}} \mathrm{R}^{2}$ and $\mathrm{J}_{\delta}=\frac{1}{3} \mathrm{M}_{\mathrm{B}}\left[\frac{\mathrm{D}}{2}\right]^{2}=\frac{1}{12} \mathrm{M}_{\mathrm{B}} \mathrm{D}^{2}$

Substituting equation (31) into equation (30), we have equation (32)

$\ddot{\delta}=\mathrm{C}_{3} \mathrm{C}_{\delta}$

State space representation of the Segway as a non-linear system can be described by equations (25, $26,32)$, where total torque required to change pitch angle is $\mathrm{C}_{\theta}=\mathrm{C}_{\mathrm{L}}+\mathrm{C}_{\mathrm{R}}$ and total torque required to change yaw angle is $C_{\delta}=C_{L}-C_{R}$.

$A=2 M_{g}+M_{B}-\frac{0.75\left(M_{W} R+M_{B} L \cos \theta\right) \cos \theta}{L}$

$$
\begin{aligned}
& \mathrm{B}_{1}=\frac{0.75 \mathrm{~g}\left(2 \mathrm{M}_{\mathrm{W}}+\mathrm{M}_{\mathrm{B}}\right) \sin \theta}{\mathrm{L}}-\frac{0.75 \mathrm{M}_{\mathrm{B}} \mathrm{L} \sin \theta \cos \theta}{\mathrm{L}} \dot{\theta}^{2} \\
& \mathrm{C}_{1}=-\left(\frac{0.75\left(1+\sin ^{2} \theta\right)\left(2 \mathrm{M}_{\mathrm{W}}+\mathrm{M}_{\mathrm{B}}\right)}{\mathrm{M}_{\mathrm{B}} \mathrm{L}^{2}}+\frac{0.75 \cos \theta}{\mathrm{RL}}\right) \\
& \mathrm{B}_{2}=\frac{-0.75 \mathrm{~g}\left(\mathrm{M}_{\mathrm{W}} \mathrm{R}+\mathrm{M}_{\mathrm{B}} \mathrm{L} \cos \theta\right) \sin \theta}{\mathrm{L} L \mathrm{M}_{\mathrm{B}} \mathrm{L} \sin \theta \dot{\theta}^{2}} \\
& \mathrm{C}_{2}=\frac{-0.75\left(\mathrm{M}_{\mathrm{W}} \mathrm{R}+\mathrm{M}_{\mathrm{B}} \mathrm{L} \cos \theta\right)\left(1+\sin ^{2} \theta\right)}{\mathrm{M}_{\mathrm{B}} \mathrm{L}^{2}}+\frac{1}{\mathrm{R}} \\
& \mathrm{C}_{3}=\frac{6}{\left(9 \mathrm{M}_{\mathrm{W}}+\mathrm{M}_{\mathrm{B}}\right) \mathrm{RD}}
\end{aligned}
$$

The Nonlinear model of Segway is linearized at $\mathrm{x}=0$. The Segway is considered in upright at the point $\mathrm{x}=0$. The Linearized equations are as follows:

$\dot{x_{1}}=\mathrm{x}_{4}$

$\dot{\mathrm{x}_{2}}=\mathrm{Qx}_{3}-2 \mathrm{SC}$

where $\mathrm{x}_{1}=$ Position of the Segway, $\mathrm{x}_{2}=$ Velocity of the Segway, $x_{3}=$ Pitch Angle of the Segway

$\mathrm{x}_{4}=$ Angular velocity of the Segway

$\mathrm{P}=\frac{0.75\left(2 \mathrm{M}_{\mathrm{W}}+\mathrm{M}_{\mathrm{B}}\right)}{2 \mathrm{M}_{\mathrm{W}} \mathrm{L}+\mathrm{M}_{\mathrm{B}} \mathrm{L}-0.75\left(\mathrm{M}_{\mathrm{W}} \mathrm{R}+\mathrm{M}_{\mathrm{b}} \mathrm{L}\right)}$

$\mathrm{Q}=\frac{-0.75 \mathrm{~g}\left(\mathrm{M}_{\mathrm{W}} \mathrm{R}+\mathrm{M}_{\mathrm{B}} \mathrm{L}\right)}{\left(2 \mathrm{M}_{\mathrm{W}} \mathrm{L}+\mathrm{M}_{\mathrm{B}} \mathrm{L}\right)-0.75\left(\mathrm{M}_{\mathrm{W}} \mathrm{R}+\mathrm{M}_{\mathrm{W}} \mathrm{R}+\mathrm{M}_{\mathrm{B}} \mathrm{L}\right)}$

$R=\frac{0.75 R\left(2 M_{W}+M_{B}\right)-\left(0.75 M_{B} L\right)}{M_{B} L R\left(2 M_{W} L+M_{B} L-0.75\left(M_{W} R+M_{B} L\right)\right)}$

$S=\frac{0.75\left(M_{W} R+M_{B} L\right) R+M_{B} L^{2}}{M_{B} L R\left(2 M_{W} L+M_{B} L-0.75\left(M_{W} R+M_{B} L\right)\right)}$

State Space equations of the Linearized model of the Segway system are

$\dot{\mathrm{x}}=\mathrm{Ax}+\mathrm{Bu}$

$\mathrm{y}=\mathrm{Cx}+\mathrm{Du}$

where

$A=\left[\begin{array}{llll}0 & 1 & 0 & 0 \\ 0 & 0 & \mathrm{Q} & 0 \\ 0 & 0 & 0 & 1 \\ 0 & 0 & \mathrm{P} & 0\end{array}\right]$,
$\mathrm{B}=\left[\begin{array}{c}0 \\ -2 \mathrm{SR} \\ 0 \\ 2 \mathrm{R}\end{array}\right]$
$\mathrm{C}=\left[\begin{array}{llll}1 & 0 & 0 & 0 \\ 0 & 0 & 1 & 0\end{array}\right]$
$\mathrm{D}=\left[\begin{array}{l}0 \\ 0\end{array}\right]$ 
$\mathrm{x}=\left[\begin{array}{l}\mathrm{x}_{1} \\ \mathrm{x}_{2} \\ \mathrm{x}_{3} \\ \mathrm{x}_{4}\end{array}\right]$

\begin{tabular}{|c|c|c|}
\hline \multicolumn{3}{|c|}{ Table 1: Parameters of the Two Wheeled Segway } \\
\hline Symbol & $\begin{array}{l}\text { Value } \\
\text { [Unit] }\end{array}$ & Parameters \\
\hline$\theta$ & [rad] & Pitch Angle of Segway \\
\hline$\delta$ & [rad] & Yaw angle of Segway \\
\hline $\mathrm{M}_{\mathrm{w}}$ & $7[\mathrm{~kg}]$ & Wheel mass \\
\hline $\mathrm{M}_{\text {rider }}$ & $80[\mathrm{~kg}]$ & Rider mass \\
\hline $\mathrm{M}_{\mathrm{S}}$ & $26[\mathrm{~kg}]$ & Segway mass \\
\hline $\mathrm{M}_{\mathrm{B}}$ & {$[\mathrm{kg}]$} & $\begin{array}{l}\text { Total body mass } \\
\left(M_{B}=M_{S}+M_{\text {rider }}\right)\end{array}$ \\
\hline $\mathrm{R}$ & $0.2[\mathrm{~m}]$ & Wheel radius \\
\hline $\mathrm{L}$ & [m] & $\begin{array}{l}\text { Distance between the } \\
\text { center of the gravity of } \\
\text { Segway and } \mathrm{z} \text { axis }\end{array}$ \\
\hline $\mathrm{D}$ & $0.6[\mathrm{~m}]$ & $\begin{array}{l}\text { Distance between the } \\
\text { contact } \\
\text { points of the two wheels }\end{array}$ \\
\hline $\mathrm{g}$ & $9.8\left[\mathrm{~m} / \mathrm{s}^{2}\right]$ & Constant of Gravity \\
\hline $\mathrm{H}_{\mathrm{B}}$ & $0.03[\mathrm{~m}]$ & Body height \\
\hline $\mathrm{L}_{\text {rider }}$ & $1.8[\mathrm{~m}]$ & Rider height \\
\hline $\mathbf{J}_{\text {rider }}$ & {$\left[\mathrm{kgm}^{2}\right]$} & Rider inertia \\
\hline $\mathrm{J}_{\mathrm{B}}$ & {$\left[\mathrm{kgm}^{2}\right]$} & Body pitch inertia \\
\hline $\mathrm{C}_{\mathrm{L}}, \mathrm{C}_{\mathrm{R}}$ & [N.m] & $\begin{array}{l}\text { Torques at the inputs of } \\
\text { left and right wheels }\end{array}$ \\
\hline $\begin{array}{l}\mathrm{H}_{\mathrm{TL}} \\
\mathrm{H}_{\mathrm{TR}}\end{array}$ & {$[\mathrm{N}]$} & $\begin{array}{l}\text { Friction between the } \\
\text { wheels and ground } \\
\text { surface }\end{array}$ \\
\hline $\mathrm{H}_{\mathrm{L}}, \mathrm{H}_{\mathrm{R}}$ & {$[\mathrm{N}]$} & $\begin{array}{l}\text { Impact of Reaction } \\
\text { forces on the left and } \\
\text { right wheels. }\end{array}$ \\
\hline $\mathbf{J}_{\mathrm{TL}}, \mathbf{J}_{\mathrm{TR}}$ & {$\left[\mathrm{kgm}^{2}\right]$} & $\begin{array}{l}\text { Moment of Inertia of the } \\
\text { rotating masses with } \\
\text { reference to the } \mathrm{z} \text { axis }\end{array}$ \\
\hline $\begin{array}{l}\theta_{\mathrm{WL}} \\
\theta_{\mathrm{WR}} \\
\end{array}$ & [rad] & $\begin{array}{l}\text { Angle of the left and } \\
\text { right wheels }\end{array}$ \\
\hline
\end{tabular}

\section{CONTROLLER DESIGN}

The main features of the proposed hybrid control strategy are described as follows:

- Design of mixed sensitivity-based $\mathrm{H}_{\infty}$ robust controller to keep the Segway in equilibrium position having tilt angle $\theta=0^{0}$, i.e. to ensure the upward stabilization of human rider.

- A right and left-turning control system designed to control the Segway in turning right and left. In this paper, an LQR control system is used to design a right- and left-turning of the Segway.

\section{1 $\mathrm{H}_{\infty}$ Control System Design}

$\mathrm{H}_{\infty}$ controller design methodology has a number of advantages which include stability, disturbance rejection, robustness and it also caters modelling errors. Design specifications such as uncertainty in model [23], reference tracking at lower frequencies and disturbance rejection at higher frequencies are generally addressed in $\mathrm{H}_{\infty}$ controller design techniques. This technique provides a close loop response of the system based on the bandwidth which is specified by appropriate performance weights selection. $\mathrm{H}_{\infty}$ controller design technique incorporates the weights which depend on frequency and are responsible for shaping the closed loop system's response.

In this work, the rider's mass has been taken as a modeling uncertainity because the exact mass of the rider in unknown at the time, i.e. different riders possess different mass.

\subsection{Generalized Problem Formulation}

Feedback controller design may have many control configurations but it is useful to have a generalized configuration so that every problem can be formulated according to the requirements [24]. Such a generalized control configuration is shown in Fig. 3.

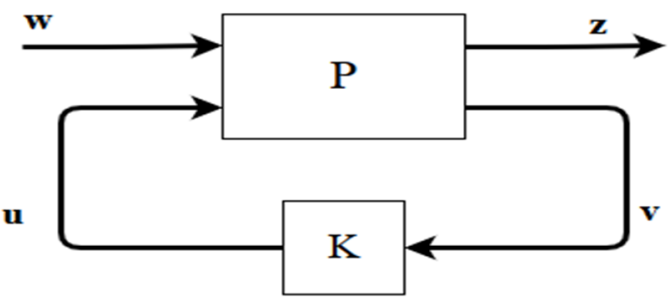

Fig. 3: Generalized Control Configuration

Generalized control configuration of the system is

$$
\begin{aligned}
& {\left[\begin{array}{l}
\mathrm{z} \\
\mathrm{v}
\end{array}\right]=\mathrm{P}(\mathrm{s})\left[\begin{array}{l}
\mathrm{w} \\
\mathrm{u}
\end{array}\right]=\left[\begin{array}{ll}
\mathrm{P}_{11}(\mathrm{~s}) & \mathrm{P}_{12}(\mathrm{~s}) \\
\mathrm{P}_{21}(\mathrm{~s}) & \mathrm{P}_{22}(\mathrm{~s})
\end{array}\right]} \\
& \mathrm{u}=\mathrm{K}(\mathrm{s}) \mathrm{v}
\end{aligned}
$$

where $\mathrm{u}=$ variables to control., $\mathrm{v}=$ variables to be measured, $\mathrm{w}=$ outer signals disturbances and references, $\mathrm{z}=$ signals to be minimized to achieve the control objectives. 
The linear fractional transformation gives the closed loop transfer function between $\mathrm{w}$ and $\mathrm{z}$.

$\mathrm{z}=\mathrm{F}_{1}(\mathrm{P}, \mathrm{K}) \mathrm{w}$

where

$\mathrm{F}_{1}(\mathrm{P}, \mathrm{K})=\mathrm{P}_{11}+\mathrm{P}_{12} \mathrm{~K}\left(\mathrm{I}-\mathrm{P}_{22} \mathrm{~K}\right)^{-1} \mathrm{P}_{21}$

The $\mathrm{H}_{\infty}$ controller minimizes the $\mathrm{H}_{\infty}$ norm of the lower fractional transform $\boldsymbol{F}_{\boldsymbol{l}}(P, \mathrm{~K})$.

\subsection{Generalized $\mathbf{H}_{\infty}$ Loop Shaping Design}

There are multiple methods for designing of $\mathrm{H}_{\infty}$ controller but loop shaping design is most popular because of its simple design procedure and ability to deal with a broad class of uncertainties [23]. Postlethwaite and Skogestad [24] proposed a design of loop shaping for $\mathrm{H}_{\infty}$ controller. This technique is a combination of loop shaping and robust stabilization.

There are two steps involved in loop shaping design procedure.

(1) Augmentation of plant with pre and post compensator.

(2) Stabilization of shaped plant using coprime uncertainty optimization

Loop shaping design is preferred over other techniques of $\mathrm{H}_{\infty}$ controller design, as robust stabilization problem does not require any $\gamma$ iterations to reach at a solution [24]. Moreover, the weight selection or problem dependent uncertainty is not required for the design. As there are no weights on the perturbations so it is reasonable for the nominal plant to use normalized coprime factorization. This description of uncertainty is general and is advantageous when we do not have specific information about the uncertainties in the plant as it represents a broad class of uncertainties and allows the movement of both zeroes and poles from left half plane to right half plane.

\subsection{Mixed SensitivityH $\mathrm{H}_{\infty}$ Control}

In mixed sensitivity, we used sensitivity function which mathematically written as $\mathrm{S}=(\mathrm{I}-\mathrm{GK})^{-1}$ is shaped for closed loop transfer functions for example KS or the complementary transfer function $\mathrm{T}=\mathrm{I}-\mathrm{S}$ and such type of problems are called mix sensitivity optimization shaping problems as shown in Fig. 4.

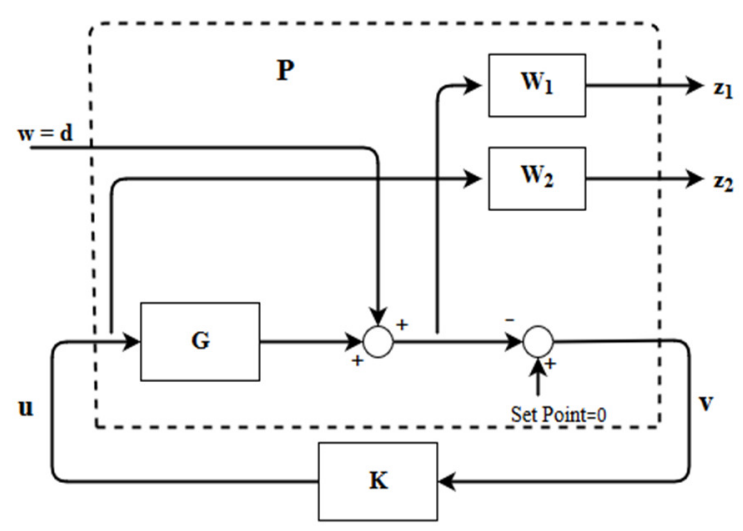

Fig. 4. $\mathrm{H}_{\infty}$ Mixed Sensitivity in Standard Form (Disturbance Rejection)

$\mathrm{w}_{1}(\mathrm{~s})=$ Scalar low pass filter

$\mathrm{w}_{2}(\mathrm{~s})=$ Scalar high pass filter

$\left\|\begin{array}{c}\mathrm{w}_{1} \mathrm{~S} \\ \mathrm{w}_{2} \mathrm{KS}\end{array}\right\|_{\infty}$

In General, mixed sensitivity problem can be expressed as:

Error signal: $\mathrm{z}=\left[\mathrm{z}_{1}^{\mathrm{T}} \mathrm{z}_{2}^{\mathrm{T}}\right]^{\mathrm{T}}$

$\mathrm{z}_{1}=\mathrm{W}_{1 \mathrm{y}}$

$\mathrm{z}_{2}=-\mathrm{W}_{\mathrm{u}}$

According to figure configuration of (3).

$\mathrm{z}_{1}=\mathrm{W}_{1} \mathrm{Sw}$

$\mathrm{z}=\mathrm{W}_{2} \mathrm{KSw}$

So elements of generalized power plant $\mathrm{P}$ are:

$\mathrm{P}_{11}=\left[\begin{array}{c}\mathrm{W}_{1} \\ 0\end{array}\right]$

$P_{12}=\left[\begin{array}{c}W_{1} G \\ -W_{2}\end{array}\right]$

$\mathrm{P}_{21}=-\mathrm{I}$

$P_{22}=-G$

$\mathrm{H}_{\infty}$ controller minimizes the $\mathrm{H}_{\infty}$ norm of the fractional transform $F_{l}(P, \mathrm{~K})$.

$\mathrm{F}_{1}(\mathrm{P}, \mathrm{K})=\left[\begin{array}{c}\mathrm{W}_{1} \mathrm{~S} \\ \mathrm{~W}_{2} \mathrm{KS}\end{array}\right]$

\subsection{LQR Controller to Control the Yaw Angle of Segway}

Linear Quadratic Regulator (LQG) technique is 
is related to the theory of optimal control in which a cost function is to be minimized to solve LQ problems. This technique is used with some other techniques like Routine Kalman Filtering to get best control response for the naturally unstable systems $[25,26]$.

To control the Yaw angle of the Two Wheeled Segway, LQR-control can be applied. The general configuration of LQR is shown in Fig. 5.

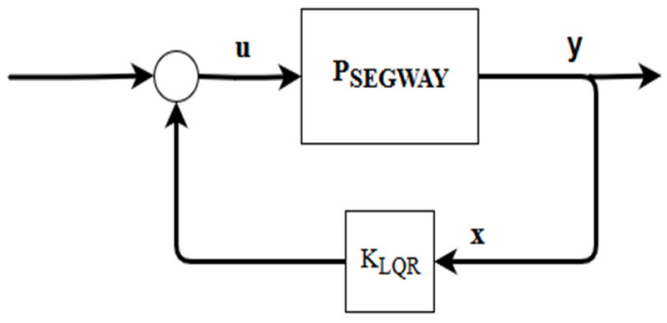

Fig. 5: Block Diagram of LQR Controller for the System (Segway)

The cost function of the performance index is given by

$J=\int_{0}^{\infty}\left(X^{T} Q X+u^{T} R u\right) d t$

For LQR Controller design, the control effort, $\mathrm{u}_{\text {input }}$ is given as:

$\mathrm{u}_{\text {input }}=-\mathrm{Kx}$

Gain matrix of $\mathrm{K}$ is defined as

$\mathrm{K}=\mathrm{R}^{-1} \mathrm{~B}^{\mathrm{T}} \mathrm{P}$

And $\mathrm{P}$ is solved from the Ricatti Equation

$\mathrm{Q}+\mathrm{A}^{\mathrm{T}} \mathrm{P}+\mathrm{PA}-\mathrm{PBB}^{\mathrm{T}} \mathrm{P}=0$

Since the state space system is controllable and observable, $\mathrm{P}$ has the only unique solution when the state space system is observable as well as controllable, so that the closed loop system poles are strictly in the right half plane. However, it's necessary to make it clear that for a particular change in input, for example an impulse on the Segway, that the control effort $\mathrm{u}_{\text {input }}$ determine by the controller is lie within some certain bounds.

Using Equation (36), the transfer function of Yaw angle of the Segway is described as;

$$
\mathrm{G}_{\text {yawn }}(\mathrm{s})=\frac{\delta(\mathrm{s})}{\mathrm{C}_{\delta}(\mathrm{s})}=\frac{1}{\mathrm{~s}^{2}} \mathrm{C}_{3}
$$

\section{PROPOSED CONTROL DESIGN FOR THE SEGWAY}

The proposed hybrid control system for two wheeled Segway has been simulated using MATLAB Simulink. Block diagram of the Hybrid controller design is shown in Fig. 6.

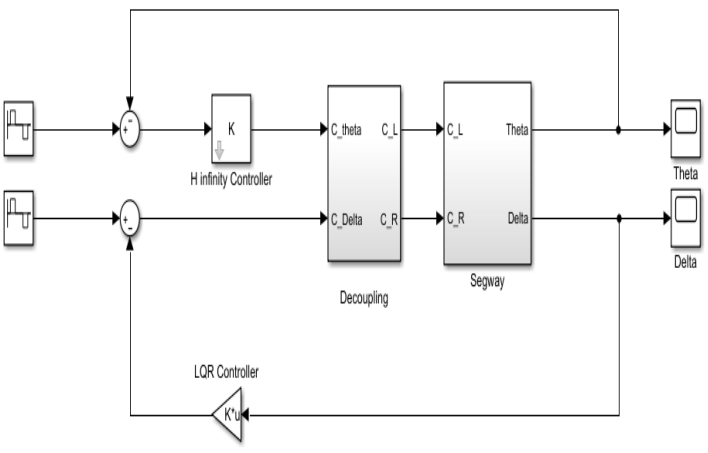

Fig. 6: Block Diagram of the Hybrid Segway Controller

The Controller $\mathrm{K}\left(\mathrm{H}_{\infty}\right)$ is achieved as:

$\mathrm{K}=$

$\frac{-2.956 \mathrm{e} 08 \mathrm{~s}^{\wedge} 3-8.01 \mathrm{e} 08 \mathrm{~s}^{\wedge} 2-2.942 \mathrm{e} 09 \mathrm{~s}-7.973 \mathrm{e} 09}{\mathrm{~s}^{\wedge} 4+1.616 \mathrm{e} 06 \mathrm{~s}^{\wedge} 3+3.172 \mathrm{e} 07 \mathrm{~s}^{\wedge} 2+5.033 \mathrm{e} 07 \mathrm{~s}+2.086 \mathrm{e} 07}$

Weights for $\mathrm{H}_{\infty}$ Mix Sensitivity Loop Shaping are:

$\mathrm{Wp}=\frac{\mathrm{s}^{2}+10.44 \mathrm{~s}+27.25}{0.007569 \mathrm{~s}^{2}+0.01285 \mathrm{~s}+0.00545} ; \mathrm{W}_{\mathrm{u}}=1$

Disturbance Transfer Function is:

$\mathrm{G}_{\mathrm{d}}=\frac{10}{50 \mathrm{~s}+500}$

\section{RESULTS AND DISCUSSIONS}

First of all, we designed the $\mathrm{S}$ function block to simulate the non-linear response of two wheeled Segway. The results are shown in Figs. 7-12.

\subsection{Open loop analysis}

In Figs. 7-8, the analysis shows that the open loop system is unstable. So, it is required to design a control system to stabilize the response for both pitch and yaw angles. 


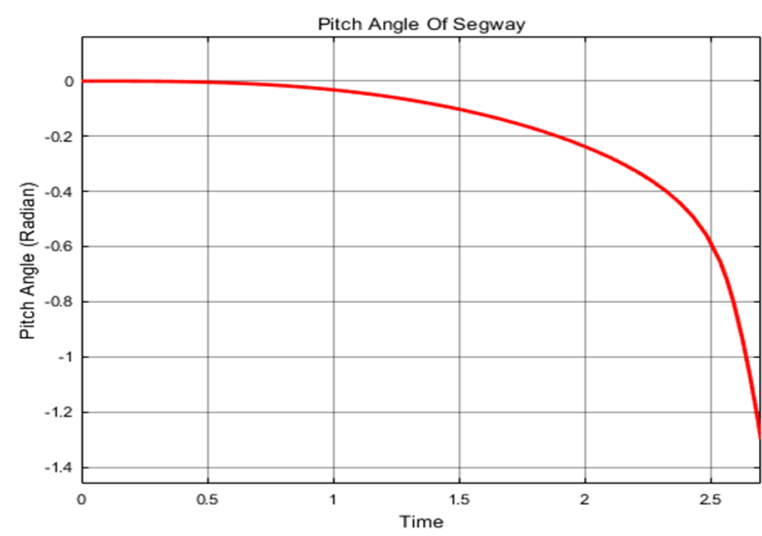

Fig. 7: Step Response of the Segway Pitch Angle

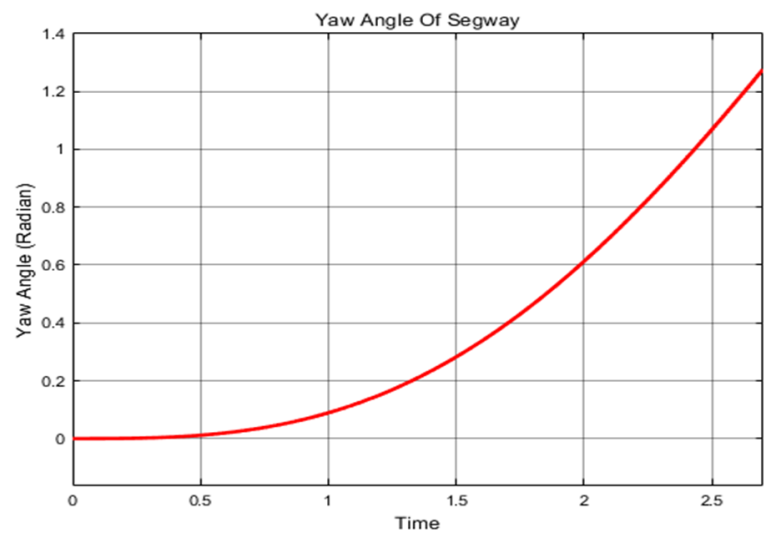

Fig. 8: Step Response of the Segway Yaw Angle

\subsection{Results of Hybrid Control System}

In Fig. 9, the simulation results illustrate that in response of the square wave disturbance, which is to the tilt angle of the Segway, the Segway angle disturbs to only $0.1 \mathrm{rad} / \mathrm{s}$ and comes back to its equilibrium value within less than 0.5 seconds. The overshoot is very small.

In Fig. 10, the control effort of the controller in Nm reaches only $18 \mathrm{Nm}$ which is very less as compared to the back- stepping technique. This ensures the effectiveness of $\mathrm{H}_{\infty}$ controller.

The simulation results in Fig. 11 illustrate that the settling time is almost 0.2 seconds for LQR Control design. So, the overall Hybrid controller design shows the reasonable results in terms of both disturbance rejection and control effort. All the simulations are performed for 0.1 radian change in Segway Pitch and Yaw angles. The Yaw angle of the Segway is also controlled effectively using LQR controller.

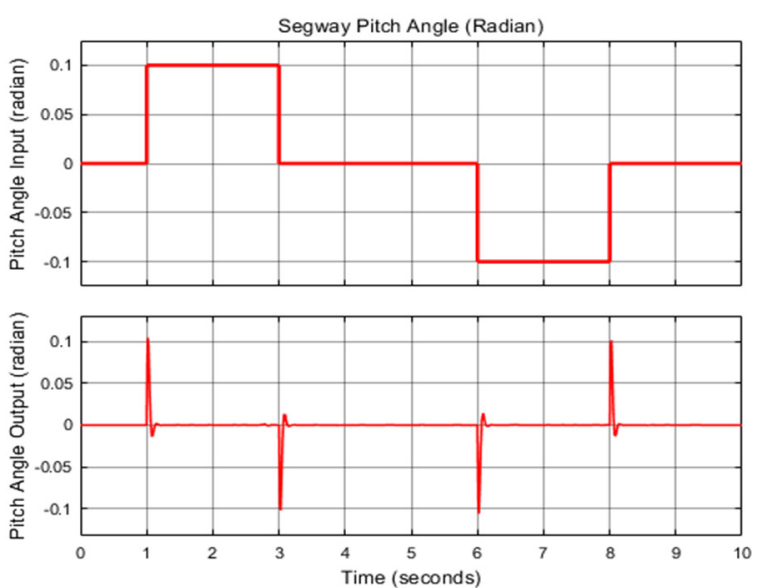

Fig. 9: Segway Pitch Angle Response for 0.1 Radian Change
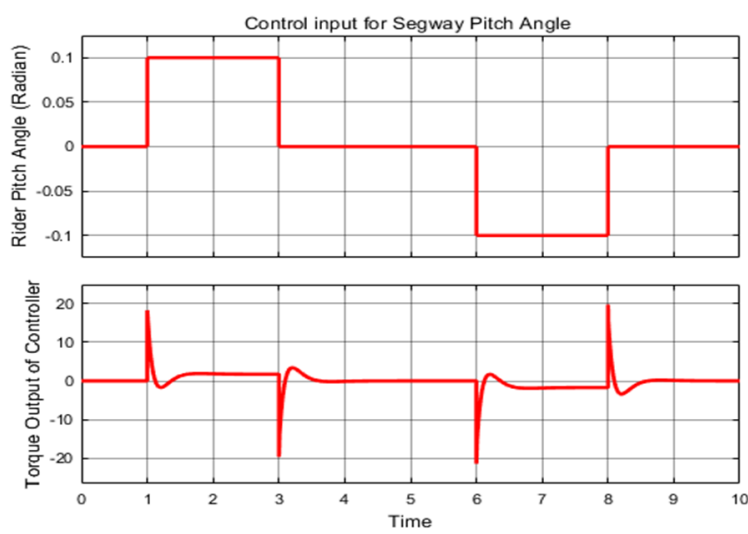

Fig. 10: Torque Output of Pitch Angle Controller for 0.1 Radian Change

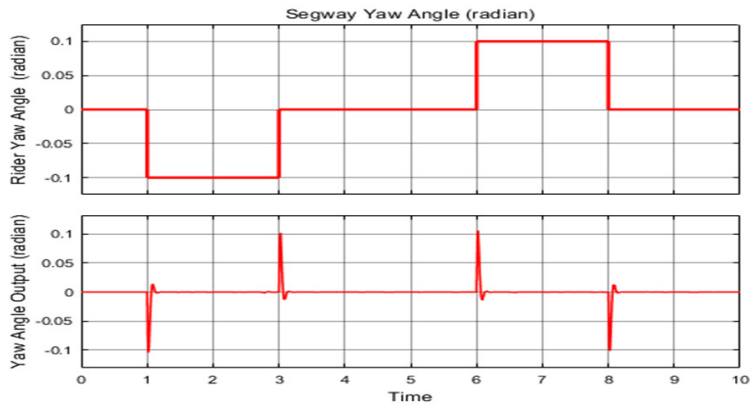

Fig. 11: Segway Yaw Angle Response for 0.1 Radian Change

\subsection{Relationship between Torque Difference and Yaw Angle}

A right and left-turning control system is designed to control the Segway in turning right and left. A change in yaw angle is required to turn Segway left and right. According to Fig. 12, when torque applied on left 
wheel $\left(\mathrm{C}_{\mathrm{L}}\right)$ is greater than right wheel $\left(\mathrm{C}_{\mathrm{R}}\right)$ then variation in delta is positive so Segway will move to right side. Similarly, when torque applied on right wheel $\left(C_{R}\right)$ is greater than left wheel $\left(C_{L}\right)$ then variation in delta is negative so Segway will move to left side.

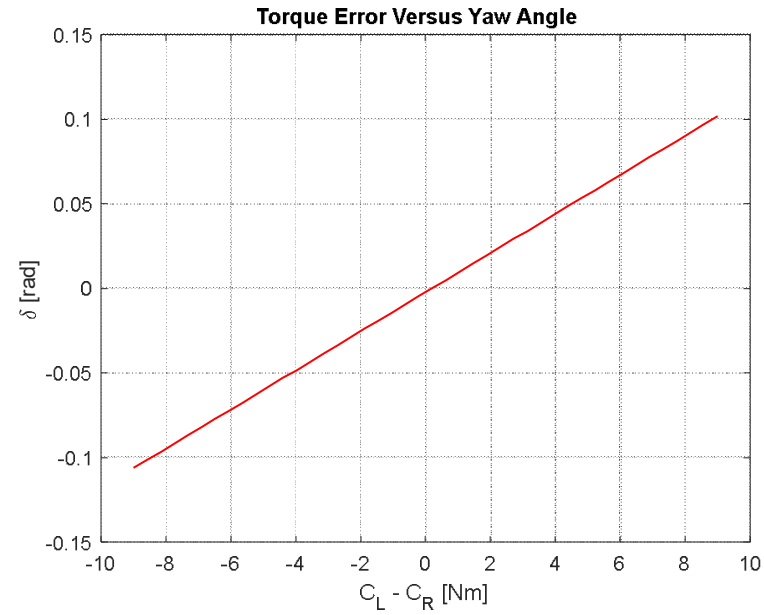

Fig. 12: Relationship between Torques Vs Yaw Angle (Delta)

The comparison between the proposed hybrid approach and Backstepping control strategy is given in Table 2. The Table 2 shows that the control effort achieved by applying the proposed technique is much lesser compared to that of using Backstepping in [21].

\begin{tabular}{|c|c|c|c|}
\hline \multicolumn{4}{|c|}{ Table 2: Comparisons between Backstepping and } \\
Proposed Technique \\
\hline Technique & $\begin{array}{c}\text { Peak } \\
\text { Value } \\
\text { (rad) }\end{array}$ & $\begin{array}{c}\text { Settling } \\
\text { Time } \\
\text { (Seconds) }\end{array}$ & $\begin{array}{c}\text { Control } \\
\text { Input } \\
(\mathrm{Nm})\end{array}$ \\
\hline Backstepping & 0.1 & 2.5 & 50 \\
\hline $\begin{array}{c}\text { Hybrid } \\
\text { Technique }\end{array}$ & 0.1 & 0.5 & 18 \\
\hline
\end{tabular}

\section{CONCLUSION}

A hybrid technique for the stabilization and control on one of the applications of inverted pendulum i.e. two wheeled Segway is successfully applied. Many techniques including LQR, sliding mode control, back stepping etc. are available for controlling two wheeled Segway, where every technique has its own pros and cons. Out of all these approaches, back-stepping is one of the main approaches used for upward stabilization of two wheeled Segway. The main drawback of this technique is its complexity and increased control effort.

To resolve this problem, a robust control i.e. $\mathrm{H}_{\infty}$ controller using mix sensitivity loop shaping for controlling the pitch angle of the Segway and the LQR controller to control the Yaw Angle of the Segway is combined to use to benefits of both. The simulation results of our proposed technique reveal that the disturbance rejection has been improved for a much lesser control effort compared to back stepping technique [21] and thus avoids the saturation of motors. Reducing control effort is helpful to avoid the saturation of motors which causes the failure of control system. It is a significant achievement to reduce the control effort from 50 to $18 \mathrm{Nm}$ for the Segway, which is almost $64 \%$. In future, by utilizing this hybrid technique, one can apply this approach on a real time system ensuring the reliability and increased the life span of actuators used in two wheeled Segway.

\section{ACKNOWLEDGEMENT}

The authors would like to acknowledge the Department of Electrical Engineering, University of Engineering and Technology, Taxila, Pakistan. Authors are highly grateful to anonymous reviewers for their useful suggestions.

\section{REFERENCES}

1. Kolhe V., Karole P., Patil M., "Development of Self Balance Transporter: A Segway", International Journalon Emerging Trends in Technology, Vol. 1, No. 1, pp.7094-7097, 2017.

2. Pourmand A., Liao J., Pines J. M., MazerAmirshahi M., "Segway® personal transporterrelated injuries: a systematic literature review and implications for acute and emergency care", Emergency Medicine Journal, Vol. 54, No. 5, pp. 630-635, 2018.

3. Singhose W., Adams C., Kim D.,"A DynamicsBased Hazard Analysis of Inverted-Pendulum Human Transporters Using Data-Mined Information", ASCE-ASME Journal of Risk and Uncertainty in Engineering Systems, Part B: Mechanical Engineering, Vol. 2, No. 3, pp. 31007-31019, 2016. 
4. Chan R. P. M., Stol K. A., Halkyard C. R., "Review of modelling and control of two-wheeled robots", Annual Reviews in Control, Vol. 37, No. 1, pp. 89-103, 2013.

5. Boubaker O., "The inverted pendulum benchmark in nonlinear control theory: a survey", International Journal of Advanced Robotic Systems, Vol. 10, No. 5, pp. 233-242, 2013.

6. Lee G. H., Jung S., "Line tracking control of a two-wheeled mobile robot using visual feedback", International Journal of Advanced Robotic Systems, Vol. 10, No. 3, pp. 177-185, 2013.

7. Nawawi S. W., Ahmad M. N., Osman J. H. S., "Development of a two-wheeled inverted pendulum mobile robot," Proceedings of the World Academy of Science, Engineering and Technology, Vol. 29, pp. 214-220, 2008.

8. Grasser F., D'arrigo, A., Colombi, S., and Rufer, A. C., "JOE: a mobile, inverted pendulum", IEEE Transactions on Industrial Electronics, Vol. 49, No. 1, pp. 107-114, 2002.

9. Lin S. C., Tsai C. C., "Development of a selfbalancing human transportation vehicle for the teaching of feedback control", IEEE Transactions on Education, Vol. 52, No. 1, pp. 157-168, 2009.

10. Takei T., Imamura R., "Baggage transportation and navigation by a wheeled inverted pendulum mobile robot", IEEE Transactions on Industrial Electronics, Vol. 56, No. 10, pp. 3985-3994, 2009.

11. Yau H. T., Wang C. C., Pai N. S., Jang M. J., "Robust control method applied in self-balancing two-wheeled robot", Proceedings of the Second International Symposium on Knowledge Acquisition and Modeling. Vol. 1, pp. 268-271, Wuhan, China, 30 November- 1 December 2009.

12. Wu J., Liang Y., Wang Z., "A robust control method of two-wheeled self-balancing robot," Proceedings of the 6th International Forum on Strategic Technology, Vol. 2, pp. 1031-1035, Harbin, Heilongjiang, 22-24 August 2011.

13. Kokotovic P. V., "The joy of feedback: nonlinear and adaptive", IEEE Control Systems, Vol. 12, No. 3, pp. 7-17, 1992.

14. Dumitrascu B., Filipescu A., Minzu V., "Backstepping control of wheeled mobile robots", Proceedings of the 15th International Conference on System Theory, Control and Computing, pp. 16, Sinaia, Romania, 14-16 October 2011.

15. Kausar Z., Stol K., Patel N., "The effect of terrain inclination on performance and the stability region of two-wheeled mobile robots", International Journal of Advanced Robotic Systems, Vol. 9, No.5, pp.218-229, 2012.

16. Park B. S., Yoo S. J., Park J. B., Choi Y. H., "Adaptive neural sliding mode control of nonholonomic wheeled mobile robots with model uncertainty", IEEE Transactions on Control Systems Technology, Vol. 17, No. 1, pp. 207-214, 2009.

17. Tsai C. C., Huang H. C., Lin S. C. "Adaptive neural network control of a self-balancing twowheeled scooter", IEEE Transactions on Industrial Electronics, Vol. 57, No. 4, pp. 14201428, 2010.

18. Pham D. B., Lee S. G., "Hierarchical sliding mode control for a two-dimensional ball segway that is a class of a second-order underactuated system," Journal of Vibration and Control, Vol. 25, No.1 pp. 72-83, 2019.

19. Shilpa B., Indu V., Rajasree S. R., "Design of an underactuated self balancing robot using linear quadratic regulator and integral sliding mode controller", International Conference on Circuit, Power and Computing Technologies (ICCPCT), pp. 1-6, Kollam, India, 2017.

20. Rashdi, R., Ali, Z., Larik, J. R., Jamro, L. A., and Baig, U., "Controller Design for the Rotational Dynamics of a Quadcopter," Mehran University Research Journal of Engineering and Technology, Volume 38, No. 2, pp. 269-274, 20-21 April 2019.

21. Son N. N., Anh H. P. H., "Adaptive backstepping self-balancing control of a two-wheel electric scooter", International Journal of Advanced Robotic Systems, Vol. 11, pp. 1-11, 2014.

22. Arvidsson M., Karlsson J., "Design, Construction and Verification of a Self-Balancing Vehicle", Department of Signals and Systems Chalmers University of Technology Göteborg, Sweden, 2012 .

23. Skogestad S., Postlethwaite I., "Multivariable Feedback Control: Analysis and Design", Wiley New York, Vol. 2, 2007. 
24. Postlethwaite I., Skogestad S., "Robust Multivariable Control Using $\mathrm{H}_{\infty}$ Methods, Analysis, Design and Industrial Applications", Lecture notes for short course at the 1993 European Control Conference. In Trentleman H.L., Willems J.C. (Eds.), Essays on Control: Perspectives in the Theory and its Applications, pp. 269-337, 1993.

25. McFarlane D., Glover K., "Robust Controller Design Using Normalized Coprime Factor Plant Descriptions", Lecture Notes in Control and Information Sciences, Springer, 1990.

26. Khan W., Sheeren M. K., Khan N., "On the design and characteristics of a sub-optimal observer for boeing-747", Mehran University Research Journal of Engineering and Technology, Vol. 37, No. 2, pp. 257-268, 2018. 